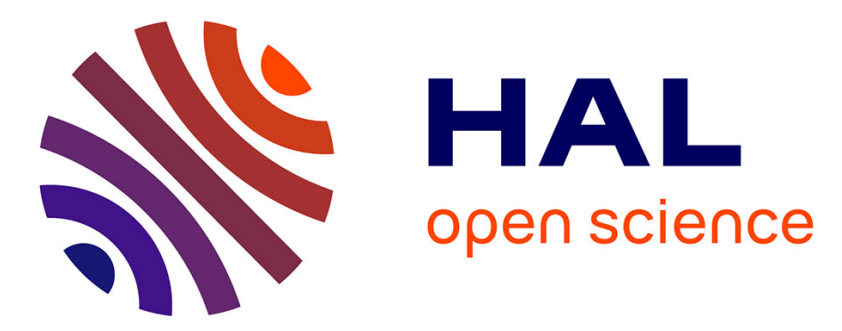

\title{
A Multidisciplinary Model of Problem Solving in Complex Production Systems
}

Ralph Riedel, Ulrike Starker, Rüdiger von Der Weth

\section{To cite this version:}

Ralph Riedel, Ulrike Starker, Rüdiger von Der Weth. A Multidisciplinary Model of Problem Solving in Complex Production Systems. IFIP International Conference on Advances in Production Management Systems (APMS), Sep 2014, Ajaccio, France. pp.387-394, 10.1007/978-3-662-44739-0_47 . hal01388518

\section{HAL Id: hal-01388518 \\ https://inria.hal.science/hal-01388518}

Submitted on 27 Oct 2016

HAL is a multi-disciplinary open access archive for the deposit and dissemination of scientific research documents, whether they are published or not. The documents may come from teaching and research institutions in France or abroad, or from public or private research centers.
L'archive ouverte pluridisciplinaire HAL, est destinée au dépôt et à la diffusion de documents scientifiques de niveau recherche, publiés ou non, émanant des établissements d'enseignement et de recherche français ou étrangers, des laboratoires publics ou privés.

\section{(c)(1)}

Distributed under a Creative Commons Attribution| 4.0 International License 


\title{
A Multidisciplinary Model of Problem Solving in Complex Production Systems
}

\author{
Ralph Riedel $^{1}$, Ulrike Starker ${ }^{2}$, Rüdiger von der Weth ${ }^{3}$ \\ ${ }^{1}$ Technische Universität Chemnitz, Factory Planning and Factory Management, Germany \\ ralph.riedel@mb.tu-chemnitz.de \\ ${ }^{2}$ University of Bamberg, Department of Educational Research, Germany \\ ulrike.starker@uni-bamberg.de \\ ${ }^{3}$ Dresden University of Applied Sciences, Business Administration, Human Resources Man- \\ agement and Industrial Science, Germany \\ weth@htw-dresden.de
}

\begin{abstract}
Future production systems, if they want to remain competitive, need the capability to autonomously adapt to new challenges, to learn new behavior and to solve complex problems. This leads to a changing role of the employees as part of sociotechnical (production) systems, because it's mainly their capability to cope with complex problem situations that determines the capabilities of the whole system. The paper presents a multidisciplinary, holistic approach to model and to design production systems from a problem solving perspective. The modelling architecture comprises of three interacting levels. Those are described in detail as well as the propositions which could be derived from the model and its parts.
\end{abstract}

Keywords: production system, modelling, simulation, problem solving

\section{Introduction}

Industrial companies, and therefore production and logistics systems, face new challenges such as an increasing level of globalization and networked production, a reduced and diversified workforce potential, shorter product lifecycles, etc. This leads to a changing role of humans in production systems - they need to continuously adapt to new situations, new technology, new processes and new organizations [1]. Therefore, production systems need to be designed in a way that they facilitate learning processes and that they foster the motivation and competence of workers to cope with changes, deviations from normality and disturbances. Beside cognitive capabilities, emotional factors like anxiety or confidence also play a decisive role. As a consequence certain design strategies for work systems, working processes and for the whole production systems have to meet the aforementioned requirements.

As a prerequisite a sound understanding of the basic psychological processes and their interactions with system's characteristics is absolutely necessary. Therefore, qualitatively improved models of production systems are needed to support the analysis and design of sophisticated solutions. In this paper we present a conceptual

adfa, p. 1, 2011.

(C) Springer-Verlag Berlin Heidelberg 2011 
framework for such an integrated model by which it will be possible to map and to integrate the problem solving and learning capabilities of workers in production systems based on basic emotional factors and psychological mechanisms. This extended sociotechnical model will also be able to close a transaction gap between planning and reality.

The paper is organized as follows: First we will discuss briefly the state of the art of production system modelling. In a second part we will refer to the basics of problem solving and problem solving capability. In the main part of the paper we will explain our concept of a multidisciplinary, integrated model of production systems. After a short overview of the model's architecture we will unfold its single components. Finally we will draw some conclusions and we will give an outlook on future research, also addressing some hypotheses about the behavior of the extended model.

\section{$2 \quad$ Modelling of production systems}

The planning of production systems as well as operations management is usually based on a system modelling approach, i.e. the analysis, evaluation and design of such systems is done with the help of models [2]. Such models normally cover the elements of the system (like technical equipment, products and material, workers) and their interaction (material flow, processing time etc.). Often the models are used for simulations [3] where experiments are conducted to test for example different parameter settings. Simulation-ready models can be found in a multitude of applications in production systems planning, e.g. in supply chain management and for the optimization of logistics processes [4], for transportation processes in micro- and macrologistics [5], for planning and scheduling problems [6], for the configuration of production networks and for ramp-up processes [7, 8], etc.

Usually such models cover mainly technical aspects and mirror the modelled system at its normal operation mode. Although recent approaches of artificial intelligence [9] make use of certain concepts of human information processing, the human itself as an autonomous subject and the dynamic interaction of such subjects has not yet been addressed. Also other sophisticated approaches like the person oriented simulation [10], the analysis of decision systems [11], the integration of human performance models (circadian rhythm) in simulation tools [12] or learning-capable and communicative agents in socio-cultural processes [13] have not been able to fill the gap.

It can be concluded that the demand for integrating human behavior into production system's models has already been identified [12] [14, 15]. However, there are only a few concrete modelling approaches so far and even fewer approaches with a profound psychological background which can be used for predicting human behavior in such systems. Emotional regulation, complex problem solving processes and the interaction of several subjects haven't been included in production systems models so far. 


\section{Problem solving and problem solving competence}

The main challenge in integrating human behavior in production systems emerge from modelling human behavior, which is able to solve the complex problems described above. The ability to solve complex problems refers to several demands. E.g. the most accurate test for cognitive sub-functions in complex problem solving is about "decision making", "system analysis" and "searching for mistakes" [16]. Moreover it is basic knowledge in psychology that success in problem solving is not only based on cognitive abilities and skills. In critical situations coping with problems depends highly on the actual level of subjective control $[17,18]$. If problems are increasingly new, opaque and complex, the chance to derive plans and decisions from consolidated knowledge becomes more and more improbable and this itself is a stressor by reducing the level of control. Because of that typical mistakes were found in experiments simulating complex situations. These mistakes are far beyond the intellectual level of the actors and their probability is high [19]. Generally a lower performance occurs in decision making under stress [20]. However, empirical studies show that a general high level of self-efficacy improves the performance of problem solvers [19], [21, 22]. Erpenbeck \& Rosenstiel [23] have the hypothesis that a high level of self-efficacy is also improving the tendency and ability to act autonomous in difficult situations. Self-efficacy in work situations is not a personal trait. It depends on learning in problem solving situations. In work context it depends on several aspects [24]:

- knowhow in the specific domain

- general problem solving experience

- integration in well performing organizational processes

- social support.

Studies by Starker [25] show that successful entrepreneurs have the ability to develop strategies for emotion regulation in complex situations. Students who have the ability to change actively their mood in problem solving situations have significantly better results in a computer simulated management game.

The interaction of emotion and cognitive processes in problem solving behavior was also tested in cognitive science research about action regulation. Basing on the PSI-model of Dörner [26] virtual agents have been programmed to develop strategies for survival in a fictitious micro-world [27, 28]. Different types of computer programs (emotional vs. non-emotional) and real subjects have controlled the agents in the micro-world. Artificial agents with simulated emotional functions and real subjects were more similar and showed a different behavior compared to non-emotional programs. They were also more successful. The basic principles of the emotional agents of these studies were used for developing an emotional problem solver in our own work described now. 


\section{$4 \quad$ Multidisciplinary model of production systems}

\subsection{Architecture}

To integrate human behavior in a dynamic model of the production system we have to understand the processes at three levels.

- Production model: The production system level describes the activities and interaction of machines and workers as a whole. Human behavior is the central resource for problem solving and therefore also for innovation, change and the management of dysfunctional processes. Human behavior is unique, that means two persons can behave differently in the same situation and one person will not repeat automatically the same behavior in the same situation. The production model describes, which forms of organization and processes fosters problem solving activities and which kind of human problem solving activities are improving performance and problem solving capability of the whole production system

- Incentive model: On the work system level it is described how a specific work situation impacts a specific individual. Which part of the reality is experienced on a specific work place? Which incentives and affordances exist in this work situation and how do they differ depending on the knowledge and the emotional state of the specific person? How can the work place be improved to encourage and enable people to more problem solving activity?

- Behavior model: The behavior model describes how the incentives influence the individual regulation of behavior and how this behavior influences the performances of the production system and changes it. The behavior model is dynamic. Actual control, self-efficacy, learning processes and problem solving strategies are changing in the process. This influences performance and the kind and intensity of problem solving activities.

The model shall allow insights which organizational structures, formal processes and work place designs encourage workers to solve problems autonomously and which are the prerequisites that these autonomous activities improve the problem solving capability of the whole production system.

\subsection{Production model}

The core of the extended production model covers the interaction between design parameters of the production system, the capability for problem solving and learning as well as central system indicators. The approach is presented in fig. 1. 


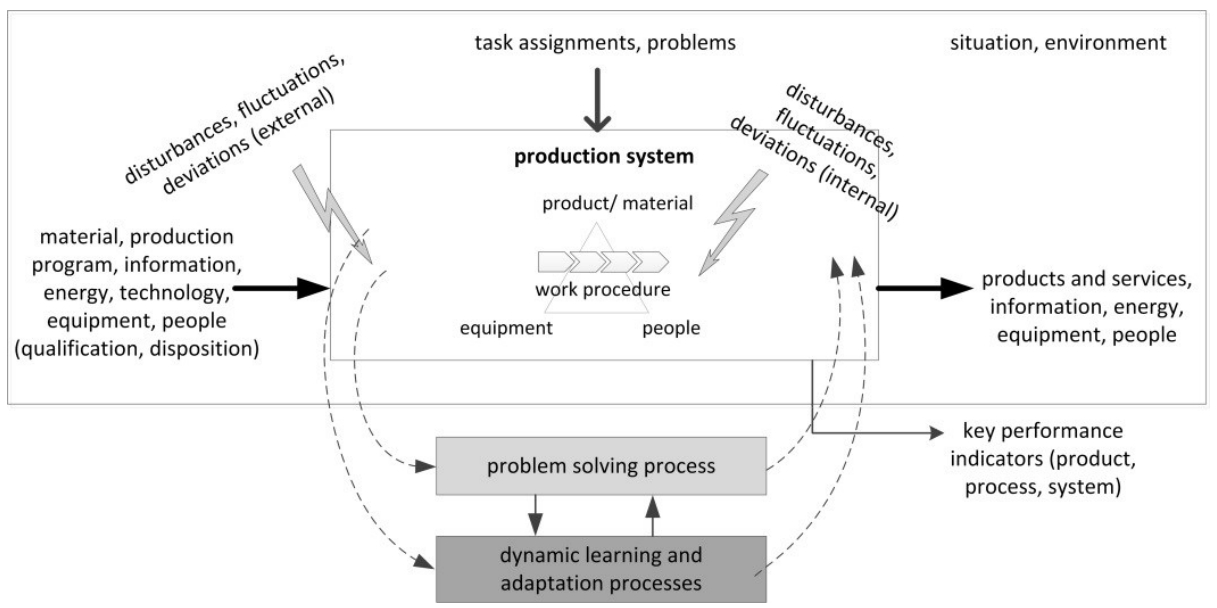

Fig. 1. Extended model of production systems

The description of problem solving and learning processes are crucial for the extended production model. Those are dependent on parameters of the situation, the task itself as well as the person. Those problem solving and learning processes are triggered by external (or even internal) assignments. Hereby, unexpected events resulting from internal or external dynamics, for instance changes in the production program, technology changes, disturbances, etc., play an important role. The problem solving and learning processes themselves lead to certain results which have an impact on the processes and stages in the production system. The system, esp. its behavior, can then be evaluated by key indicators like robustness, resilience, adaptability, productivity etc.

As the influence of structural and process parameters on economic and logistics performance indicators is already well known, the innovative core of the extended production model lies in the impact of system's design parameters on indicators for the efficient and effective reaction on disturbances, deviations and changes - see fig. 2 .

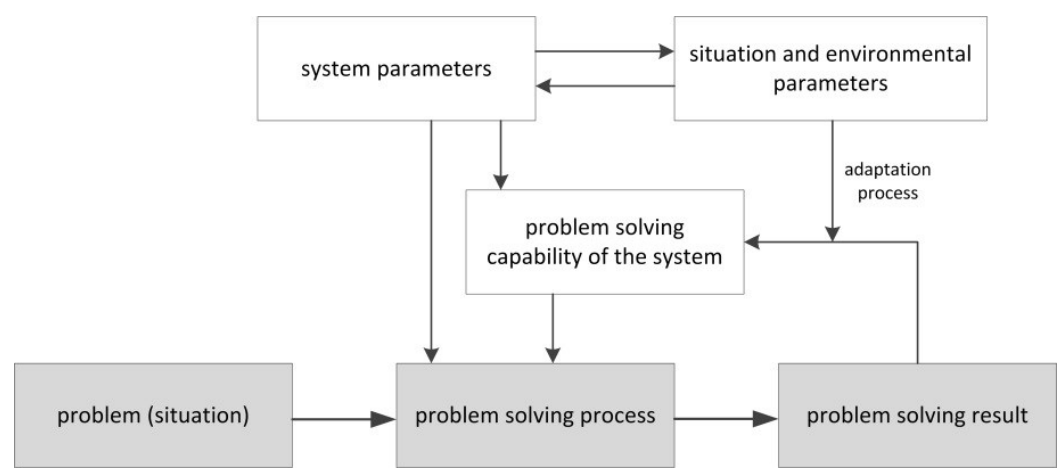

Fig. 2. Variables in the extended production model 
The knowledge about those interdependencies will finally lead to a contingency model from which the suitability of certain system's configurations under given circumstances (characteristics of the situation, of the task, of the organization, of the persons) can be derived.

The extensions of the production model need to be linked to already existing modelling concepts for production and logistics like input-output-models, process chains, etc. The extensions are among others the availability and quality of information regarding deviations and disturbances, prognosis options, alternative activities and process structures, including alternative resource allocation, etc. as well as their impact on system's performance and adaptability. For specification and formalization such approaches like "what-if-then" rules, parametric models, characteristic curves could be applied.

\subsection{Incentive model}

The incentive model is based upon classical work Lewin [29], Gibson [30] and Norman [31]. The input for this level is both the actual data of the production system and the actual state and position of the respective worker. Depending on the production data and his actual coordinates the actual perceptual field can be computed. The incentives for activities which are in this field depend on his knowledge (e.g. about the correct use of a certain tool) and his actual plans and mood. The authors are especially interested in incentives for autonomous problem solving activities. The amount of incentive varies from person to person, depending on knowledge, problem solving abilities and self-efficacy. On the other hand there exist organizational restrictions like the amount of time, which can be used for a problem solving activity, the formal rules for work in the production system for the handling of incidents and dysfunctions. Additional factors are the availability and motivation for colleagues' support.

\subsection{Behavior model}

The behavior model describes the internal processes of action regulation and how the external incentives and the cognitive and emotional prerequisites of the specific workers are computed to a behavior program. The program is an adapted version of the general PSI-agent described before. It is changed for the specific purposes of the production-system-simulation. The most important internal variable is the actual level of subjective control and the possible changes which occur when a worker follows the respective incentives of the possible alternatives. The results of his activities depend on his knowledge and his actual mood. There are three kinds of results: a change in the production system, a development of his knowledge and maybe a change in the workers mood. For starting problem solving activities the person needs an acceptable internal level of self-efficacy, knowledge and appropriate problem solving strategies. All these factors increase the tendency for autonomous problem solving activity for the specific individual. This tendency becomes even stronger when the organizational framework supports social interaction and mutual help. 


\section{Conclusion and outlook}

As discussed the proposed model should be able to allow better prognoses about autonomous problem solving behavior of workers in corresponding production processes in reality. The next important step will be to develop the validity and explanatory capability of the model. At the moment a real production system in a laboratory setting is planned which should serve as benchmark towards the prognoses of an also more sophisticated simulation model. A first simulation based upon the model produced plausible results about fictitious workers' behavior in a production system [32] and proofed the feasibility of the approach. Planned experiments will lead to insights on how certain configurations of production systems and workers with specific prerequisites influence the readiness for problem solving activities. By comparing the prognoses of the model with real human behavior in the laboratory production system, the model will be improved step by step (so called corner stone method). The long term objective of the presented and continuing research work is a better understanding in which way the organization of production systems and the design of work places, processes and working conditions influence problem solving in production systems.

\section{References}

1. Rösio, C., Säfsten, K: Reconfigurable production system design - theoretical and practical challenges. In: J. of Manufacturing Technology Management 24 (7), 998-1018 (2013)

2. VDI 5200: Factory planning - Planning procedures. VDI, Düsseldorf (2011)

3. VDI 3633: Simulation of systems in materials handling, logistics and production. VDI, Düsseldorf (1993)

4. Chang, Y., Makatsoris, H.: Supply Chain Modelling Using Simulation. In: International Journal of Simulation 2 (1), 24-30 (2001)

5. Dangelmaier, W., Mueck, B.: Using Dynamic Multiresolution Modeling to Analyze large Material Flow Systems. In: Ingalls, R. G., Rossetti, M. D., Peters, B. A., Smith, J. S. (eds.): Proceedings of the 2004 Winter Simulation Conference (WSC'04), pp. 1720-1727, (2004)

6. Hildebrandt, T., Heger, J., and Scholz-Reiter, B.: Towards improved dispatching rules for complex shop floor scenarios: a genetic programming approach. In: Proceedings of the 12th Annual Conference on Genetic and Evolutionary Computation, pp. 257-264, Portland/ Oregon (2010)

7. Weiler, S., Páez, D., Chun, J.-H., Graves, S., Lanza, G.: Supply chain design for the global expansion of manufacturing capacity in emerging markets. In: CIRP Journal of Manufacturing Science and Technology 4 (3), 265-280 (2011)

8. Fleischer, J., Lanza, G., Ender, T.: A Dynamic Business-Process Based Production Rampup Simulation Model. In: Production Engineering Research and Development XIII (2), pp. 107-110, Hannover (2006)

9. Scholz-Reiter, B., Rippel, D., Sowade, S.: A Concept for Simulation of Autonomous Logistic Processes. In: International Journal of Systems Applications, Engineering \& Development, 5(3), 324-333 (2011)

10. VDI 3633/6: Representation of human resources in simulation models. VDI, Düsseldorf (2001) 
11. Zülch, G.: Modelling and Simulation of Human Decision Making in Manufacturing Systems. In: Perrone, L. F., Wieland F. P., Lawson J., Liu B. G., Nicol D. M., Fujimoto R. M. (eds.): Proceedings of the 2006 Winter Simulation Conference (2006)

12. Baines, T. S., Mason, S., Siebers, P. -O: Humans: the missing link in manufacturing simulation? In: Simulation Modelling Practice and Theory (12), 515-526 (2004)

13. Sun, R.: The CLARION cognitive architecture: Extending cognitive modeling to social simulation In: Sun, R. (ed.): Cognition and Multi-Agent Interaction. Cambridge University Press, New York (2006)

14. Grabot, B., Marsina, S., Mayere, A., Riedel, R., Williams, P.: A socio-technical view on Supply Chain Management problems. In: Karwowski, W., Trzcielinski, S. (eds.): Value Stream Activities Management: HAAMAHA 2007 - Managing Enterprise of the Future, pp. 240-253, IEA Press, Poznan (2007)

15. Riedel, R., Fransoo, J., Wiers, V., Fischer, K., Cegarra, J., Jentsch, D.: Building Decision Systems for Acceptance. In: Fransoo, J.C., Waefler, T., and Wilson, J.R. (eds.): Behavioral Operations in Planning and Scheduling. Springer, Heidelberg (2010)

16. Leutner, D., Fleischer, J., Wirth, J., Greiff, S., \& Funke, J.: Analytical and dynamical problem solving... In: Psychologische Rundschau 63, 34-42 (2012) in German

17. Selye, H.: Stress and disease. Science 122, 625-631 (1955)

18. Lazarus, R.S.: Emotion and adaption. Oxford University Press, New York (1991)

19. Dörner, D.: The logic of failure. Metropolitan Books, New York (1996)

20. Cannon-Bowers, J.A., Salas, E.: Making decisions under stress: implications for individual and team training. American Psychological Association, Washington DC (1998)

21. Bandura, A.: Self-efficacy: Toward a unifying theory of behavioral change. In: Psychological Review 84, 191-215 (1977)

22. Jerusalem, M., Pekrun R.: Emotion, Motivation and Performance. Hogrefe, Göttingen (1999) in German

23. Erpenbeck, J. \& Rosenstiel, L.v. (eds): Handbook competence measurement: recognizing, understanding and evaluating competencies in organizations, pedagogy and psychology. Schäfer-Poeschel, Stuttgart (2007) in German

24. Von der Weth, R., Starker, U.: Integrating motivational and emotional factors in implementation strategies for new enterprise planning software. In: Production Planning and Control 21 (4) 375-385 (2010)

25. Starker, U.: Emotional Adaptivity. Pabst, Lengerich (2012) in German

26. Dörner, D.: Blueprint of a soul. Rowohlt, Reinbek /Hamburg (1999) in German

27. Dörner, D., Starker, U.: Should successful agents have emotions? In: Proceedings of the Sixth International Conference on Cognitive Modelling, pp. 344-345, Lawrence Erlbaum, Mahwah, NJ (2004)

28. ElKady, A., Starker, U.: Simulating different human Action Strategies in Uncertain Environments. In: Opwis, K., Penner, I. (eds): Proceedings of Kogwis 2005. Schwabe, Basel (2005)

29. Norman, D. A.: The psychology of everyday things. Basic Books, New York (1988)

30. Lewin, K.: Main Features of a topological Psychology. Huber, Bern (1969) in German

31. Gibson, J.J.: The Theory of Affordances. In: Shaw, R., Bransford, J. (eds.): Perceiving, Acting, and Knowing: Toward an Ecological Psychology, pp. 67-82, Hillsdale, NJ: Lawrence Erlbaum (1977)

32. Riedel, R., Müller, E., von der Weth, R., Pflugradt, N.: Integrating Human Behaviour into Factory Simulation - a Feasibility Study. In: Proceedings of the IEEE International Conference on Industrial Engineering and Industrial Management. Hong Kong (2009) 